\title{
PROPERTIES OF BUBBLE SWARM IN A SLURRY BUBBLE COLUMN
}

\author{
MIKI FUKUMA, KATSUHIKO MUROYAMA \\ AND AKIRA YASUNISHI \\ Department of Environmental Chemistry and Technology, Tottori University, \\ Tottori 680
}

Key Words: Chemical Reactor, Slurry Bubble Column, Bubble Column, Bubble Size Distribution, Bubble

Velocity Distribution, Mean Bubble Diameter

\begin{abstract}
The effects of solid concentration and liquid viscosity on bubble properties such as bubble size and bubble rising velocity were measured with a dual-electroresistivity probe in a slurry bubble column of $0.15 \mathrm{~m}$ diameter. The behavior of volume-surface mean bubble diameter, $d_{v s}$, was analyzed.

By addition of solid particles at small gas velocity, the bubble size distribution shifted to a large-size region and the bubble velocity distribution shifted to a large-velocity region. At the same time, the flow pattern changed from homogeneous flow to heterogeneous flow. The effect of solid particles on bubble size, however, became small as the particle diameter decreased or the liquid viscosity increased.

The following equation was derived to estimate $d_{v s}$.
\end{abstract}

$$
d_{v s}=0.59\left(V_{D} / \bar{\varepsilon}_{g}\right)^{2} / g
$$

where $V_{D}$ is the drift flux of gas, $\vec{\varepsilon}_{g}$ is the cross-sectionally averaged gas holdup and $g$ is the gravitational acceleration.

\section{Introduction}

Slurry bubble columns are widely used as absorbers and chemical reactors in industrial practice. Though simple in their construction, the design of slurry bubble columns, especially those with high solid content, is a difficult task because of the complexities of their hydrodynamic, heat transfer and mass transfer characteristics. Bubble properties such as bubble size and bubble velocity are important parameters in analyzing those characteristics.

A few works have been reported on the bubble characteristics in slurry bubble columns. ${ }^{7,10,13,19)}$ The effects of particle diameter, solid concentration and liquid viscosity on the bubble properties in slurry bubble columns, however, have not been made clear.

The authors investigated the fundamental properties of gas bubbles in a slurry bubble column using a dual-electroresistivity probe method and reached the following conclusions. ${ }^{19}$ )

1) The cross-sectionally averaged gas holdup, $\bar{\varepsilon}_{g}$, can be correlated well by the equation of Koide $e t$ al. ${ }^{91}$ in the range of mean solid holdup, $\bar{\varepsilon}_{s}$, less than 0.4 as follows:

$$
\begin{aligned}
& \frac{\frac{\bar{\varepsilon}_{g}}{\left(1-\bar{\varepsilon}_{g}\right)^{4}}}{=\frac{0.277\left(\frac{U_{g} \mu_{l}}{\gamma_{l}}\right)^{0.918}\left(\frac{g \mu_{l}^{4}}{\rho_{l} \gamma_{l}^{3}}\right)^{-0.252}}{1+4.35\left(\frac{C_{s}}{\rho_{s}}\right)^{0.748}\left(\frac{\rho_{s}-\rho_{l}}{\rho_{l}}\right)^{0.881}\left(\frac{D_{c} U_{g} \rho_{l}}{\mu_{l}}\right)^{-\overline{0.168}}}}
\end{aligned}
$$

where $U_{g}$ is the superficial gas velocity, $C_{s}$ the solid concentration, $\rho_{s}$ the solid density, $\rho_{l}$ the liquid density, $\mu_{l}$ the liquid viscosity, $\gamma_{l}$ the surface tension and $D_{c}$ the column diameter.

2) The bubble length distribution, $F_{l}$, follows a log-normal distribution. The bubble velocity distribution, $F_{v}$, follows a normal distribution.

3) In a slurry bubble column with high solid content, $F_{l}$ lies in a larger-size region and $F_{v}$ lies in a larger-velocity region, respectively, in comparison with the case of the bubble column.

4) $U_{g}$ has little effect on $F_{l}$ and $F_{v}$ in the slurry bubble column at high solid content.

In the present work, the effects of $\bar{\varepsilon}_{\mathrm{s}}$ and $\mu_{l}$ on $F_{l}, F_{v}$, mean bubble length and mean bubble rising velocity are investigated by using the dual-electroresistivity probe technique, ${ }^{19)}$ and an equation to correlate $d_{v s}$ with operating variables is presented. 


\section{Experimental}

The experimental system used was described in detail elsewhere. ${ }^{19)}$ The main column was $0.15 \mathrm{~m}$ in diameter and $1.2,1.7$ or $3.2 \mathrm{~m}$ in length. A multinozzle gas distributor consisting of 8 tubes of $2.6 \mathrm{~mm}$ i.d. was used. The column was equipped with two fine-mesh screens. One was the bed support at the bottom and the other was the cylindrical filter at the top. The operation was batchwise with respect to solid particles, which were suspended by a concurrent up-flow of gas and liquid. The solid concentration in the column could be maintained at a value much higher than that in the usual suspended bubble column. The liquid viscosity was changed by adding glycerol to tap water. The liquid temperature was maintained at $293.2 \mathrm{~K}$. The solid particles used were glass beads. The physical properties of the liquid used are presented in Table 1. The size of particles used and the corresponding operational conditions are presented in Table $\mathbf{2}$.

A dual-electroresistivity probe was located at a position $0.56 \mathrm{~m}$ above the bed support screen. The gas holdup was measured at 5 radial positions of $0,34,47$, 58 and $67 \mathrm{~mm}$ from the column axis with the probe. Bubble properties such as size and velocity were measured at 3 radial positions of 0,47 and $67 \mathrm{~mm}$ from the column axis with the probe. When a bubble passed through the probe points vertically (upward or downward), the bubble velocity, $U_{b}$, and the bubble length (chord length), $L_{b}$, could be calculated from the lag time between two bubble signals detected by the probe points, the duration time for the bubble and the distance between the probe points. The processing of the bubble signals from the probes was performed by use of a microcomputer. The details of the probe setup and the method for measuring the gas holdup, $U_{b}$ and $L_{b}$ were described elsewhere. ${ }^{19)}$

The local values of solid holdup, $\varepsilon_{s}$, along the column were measured prior to the measurement of bubble properties. Details of the method for measuring $\varepsilon_{s}$ and the behavior of $\varepsilon_{s}$ were discussed elsewhere. ${ }^{18)}$ When two slurry layers, i.e. the dense region and the lean region, were formed, the bubble properties were measured in the dense region and the characteristic mean solid holdup, $\bar{\varepsilon}_{s}$, was the mean of $\varepsilon_{s}$ values in the dense region. On the other hand, when $\varepsilon_{s}$ decreased continuously with axial distance, $\bar{\varepsilon}_{s}$ was taken as the mean of $\varepsilon_{s}$ values from the base to the top of the column. In both cases the value of $\bar{\varepsilon}_{s}$ was almost equal to the value of $\varepsilon_{s}$ at the axial position where the electroresistivity probe was present.
Table 1. Properties of liquids used (at 293.2 K)

\begin{tabular}{rccc}
\hline Liquid & $\begin{array}{c}\rho_{l} \\
{\left[\mathrm{~kg} / \mathrm{m}^{3}\right]}\end{array}$ & $\begin{array}{c}\mu_{l} \\
{[\mathrm{mPa} \cdot \mathrm{s}]}\end{array}$ & $\begin{array}{c}\gamma_{l} \\
{[\mathrm{mN} / \mathrm{m}]}\end{array}$ \\
\cline { 1 - 1 } Water & 998 & 1.00 & 72.8 \\
5GL & 1012 & 1.20 & 72.4 \\
16GL & 1040 & 1.70 & 71.5 \\
20GL & 1051 & 1.95 & 71.2 \\
$50 \mathrm{GL}$ & 1127 & 6.60 & 68.8 \\
\hline
\end{tabular}

5GL, 16GL, 20GL and 50GL: 5, 16, 20 and $50 \mathrm{vol} \%$ glycerol aqueous solution

Table 2. Size of glass beads and experimental conditions

\begin{tabular}{ccccc}
\hline $\begin{array}{c}d_{p} \\
{[\mathrm{~mm}]}\end{array}$ & $\begin{array}{c}\text { Mesh size } \\
{[\mathrm{mesh}]}\end{array}$ & Liquid & $\begin{array}{c}V_{\mathrm{s}} \\
{[\mathrm{cm} / \mathrm{s}]}\end{array}$ & $\begin{array}{c}\bar{\varepsilon}_{\mathrm{s}} \\
{[-]}\end{array}$ \\
\hline 0.056 & $200-400$ & Water & 0.26 & $\leq 0.4$ \\
0.16 & $80-100$ & Water & 1.63 & $\leq 0.4$ \\
& & $5 \mathrm{GL}$ & 1.42 & $\leq 0.13$ \\
& & 16GL & 1.07 & $\leq 0.13$ \\
& & 20GL & 0.94 & $\leq 0.13$ \\
0.23 & $60-65$ & WoGL & 0.29 & $\leq 0.2$ \\
0.46 & $32-35$ & Water & 2.8 & $\leq 0.4$ \\
& & Water & 6.7 & $\leq 0.5$ \\
\hline
\end{tabular}

\section{Results and Discussion}

\subsection{Effects of solid concentration and liquid viscosity on bubble properties}

Figure 1 shows the effect of mean solid holdup, $\bar{\varepsilon}_{s}$, on the bubble length distribution, $F_{l}$, and on the bubble velocity distribution, $F_{v}$, in a slurry bubble column containing $0.16 \mathrm{~mm}$ glass beads. In the figure, the logarithmic standard deviation, $\sigma_{l}$, and the median, $L_{m}$, for $F_{l}$ and the standard deviation, $\sigma_{v}$, and the median, $U_{m}$, for $F_{v}$ are noted. With increasing $\bar{\varepsilon}_{s}$, $F_{l}$ shifts to a region of large bubble size and $F_{v}$ shifts to a region of large velocity in the range of $\bar{\varepsilon}_{\mathrm{s}}<0.05$, but both remain unchanged in the range of $\bar{\varepsilon}_{s} \geq 0.05$. The values of $L_{m}$ and $U_{m}$ increase with increasing $\bar{\varepsilon}_{s}$ suddenly in a narrow range of $\bar{\varepsilon}_{s}$ from 0.02 to 0.03 , and correspondingly the flow pattern changes from homogeneous fiow to heterogeneous flow. The variation for $\sigma_{l}$ is small, however.

Figure 2 shows the effect of liquid viscosity, $\mu_{l}$, on $\sigma_{l}, L_{m}, \sigma_{v}$ and $U_{m}$ in the slurry bubble column and the bubble column. The values of these parameters for the bubble column increase with increasing $\mu_{l}$ sharply in the range of $\mu_{l}<0.002 \mathrm{~Pa} \cdot \mathrm{s}$, but slightly in the range of $\mu_{l} \geq 0.002 \mathrm{~Pa} \cdot \mathrm{s}$. On the contrary, the values of the parameters for the slurry bubble column with high solid content decrease gradually with increasing $\mu_{i}$, and agree with the corresponding values for the bubble column at high values of $\mu_{t}$.

Figure 3 shows the effect of $\bar{\varepsilon}_{s}$ on the arithmetic mean bubble length, $\bar{L}_{b}$, and the arithmetic mean bubble rising velocity, $\bar{U}_{b}$, in the slurry bubble column 


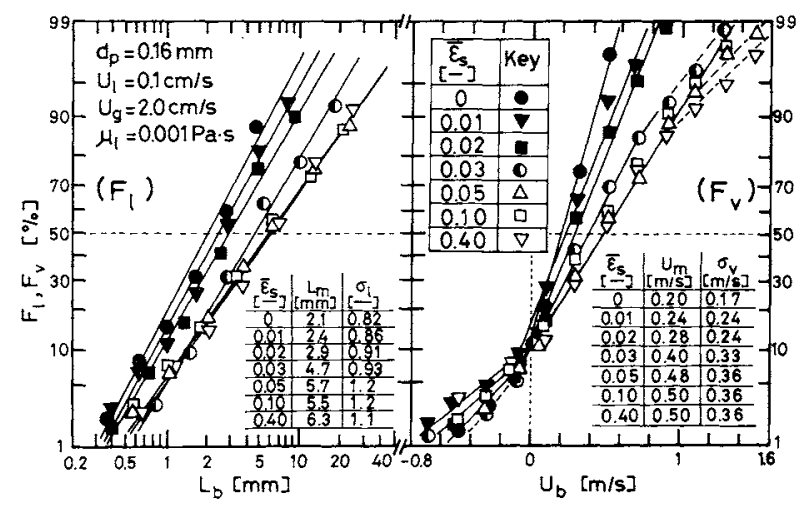

Fig. 1. Effect of $\bar{\varepsilon}_{s}$ on $F_{l}$ and $F_{v}$ at $U_{g}=2 \mathrm{~cm} / \mathrm{s}$ and $\mu_{l}=0.001 \mathrm{~Pa} \cdot \mathrm{s}$.

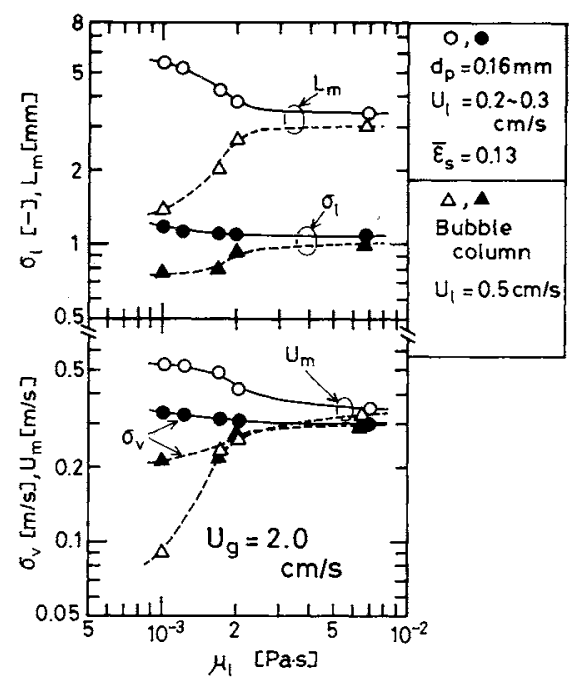

Fig. 2. Effect of $\mu_{l}$ on parameters representing the distributions of bubble properties.

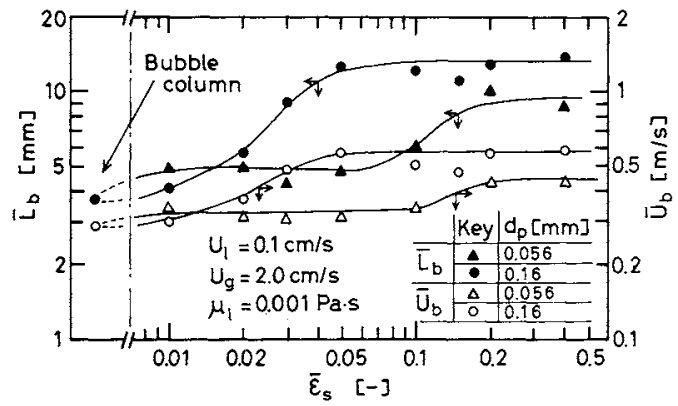

Fig. 3. Effect of $\bar{\varepsilon}_{s}$ on $\bar{L}_{b}$ and $\bar{U}_{b}$.

containing $0.16-\mathrm{mm}$ or $0.056-\mathrm{mm}$ glass beads. The values of $\bar{U}_{b}$ and $\bar{L}_{b}$ for the column with $0.16-\mathrm{mm}$ glass beads increase with increasing $\bar{\varepsilon}_{s}$ in the range of $\bar{\varepsilon}_{s}<0.05$, but both remain unchanged with further increase in $\bar{\varepsilon}_{s}$. The variation of $\bar{L}_{b}$ and that of $\bar{U}_{b}$ with respect to $\bar{\varepsilon}_{s}$ are similar to the variation of $L_{m}$ and that of $U_{m}$ shown in Fig. 1, respectively. For the column with $0.056-\mathrm{mm}$ glass beads, the variations of $\bar{L}_{b}$ and $\bar{U}_{b}$ are smaller than those for the column with 0.16$\mathrm{mm}$ glass beads. For the column with $0.056-\mathrm{mm}$ glass beads, the values of $\bar{L}_{b}$ and $\bar{U}_{b}$ remain at constant values in the range of $\bar{\varepsilon}_{s}<0.1$, then increase with increasing $\bar{\varepsilon}_{s}$ in the range of $\bar{\varepsilon}_{s}$ from 0.1 to 0.2 and attain other constant values with further increase in $\bar{\varepsilon}_{s}$. Moreover, the values of $\bar{L}_{b}$ and $\bar{U}_{b}$ for $0.056-\mathrm{mm}$ glass beads are smaller than the corresponding values for $0.16-\mathrm{mm}$ glass beads.

Figure 4 shows the effect of $\mu_{l}$ on $\bar{L}_{b}$ in the slurry bubble column and that in the bubble column for various gas velocities. In the whole range of $U_{g}$ studied, the value of $\bar{L}_{b}$ in the slurry bubble column decreases gradually with increasing $\mu_{l}$, whereas that in the bubble column increases with increasing $\mu_{i}$. Thus, at higher values of $\mu_{l}$ the values of $\bar{L}_{b}$ for the slurry bubble column may approach those for the bubble column.

\subsection{Volume-surface mean bubble diameter}

Based on the assumption that the shape of bubbles is spherical, the volume-surface mean bubble diameter, $d_{v s}$, is correlated by the following equation. ${ }^{14)}$

$$
d_{v s}=1.5 \bar{L}_{b}
$$

Figure 5 shows the variation of $d_{v s}$ in the bubble column. For the case of low viscous liquid, the value of $d_{v s}$ increases slightly with increasing $U_{g}$ in the range of $U_{g}$ less than about $2 \mathrm{~cm} / \mathrm{s}$, where the flow mode is termed homogeneous flow. ${ }^{4}$ However, the value of $d_{v s}$ increases considerably with increasing $U_{q}$ in the range of $U_{g}$ larger than about $4 \mathrm{~cm} / \mathrm{s}$, where the flow mode is termed heterogeneous flow. ${ }^{4)}$ The superficial liquid velocity, $U_{l}$, has little effect on $d_{v s}$ in the range of $U_{l}$ from 0 to $5 \mathrm{~cm} / \mathrm{s}$. On the other hand, the value of $d_{v s}$ increases with increasing $\mu_{l}$.

The values of $d_{v s}$ for air-water systems observed by various workers ${ }^{1,8,16)}$ are shown in the figure. The values of $d_{v s}$ of Ueyama et al. ${ }^{16)}$ for an air-water system based on a dual-electroresistivity probe method are almost the same in magnitude as those for this work. They used a multi-nozzle as the gas distributor. The hatched area for the volume-mean bubble diameter of Koide et al. ${ }^{8)}$ for a column with a perforated plate as gas distributor overlaps with that for $d_{v s}$ in this work. This indicates that the volumemean bubble diameter may be equivalent to $d_{v s}$ when bubble size is relatively small. On the other hand, The values of $d_{v s}$ of Akita and Yoshida ${ }^{1)}$ decrease with increasing $U_{g}$. This different trend may be attributed to the difference in measuring method for $d_{v s}$ and the difference in type of the gas distributor used; i.e., they used a photographic method for measuring $d_{v s}$ and a single orifice as the gas distributor. It may be suggested that since large bubbles, which tend to pass by in the central region of the column, cannot be clearly photographed the value of $d_{v s}$ measured by the photographic method is smaller than that measured by the electroresistivity probe method, especially at high gas 


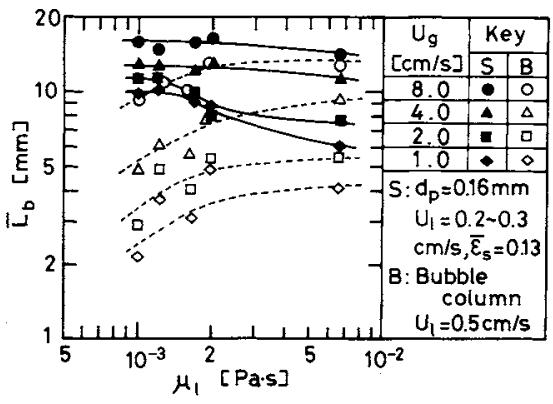

Fig. 4. Effect of $\mu_{l}$ on $\bar{L}_{b}$ in a slurry bubble column and a bubble column

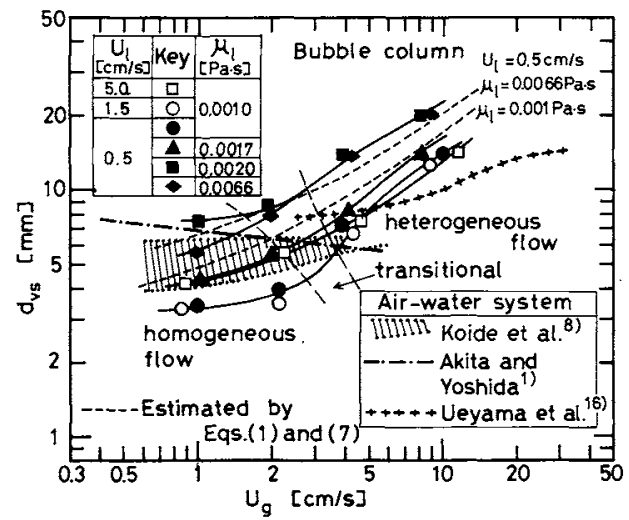

Fig. 5. Volume-surface mean bubble diameter in bubble columns.

flow rate.

Figure 6 shows the behavior of $d_{v s}$ in a slurry bubble column containing $0.16-\mathrm{mm}$ glass beads. The values of $d_{v s}$ for the column with high solid content increase slightly with increasing $U_{g}$. When $\mu_{1}$ is $0.001 \mathrm{~Pa} \cdot \mathrm{s}$, no effect of $\bar{\varepsilon}_{s}$ on $d_{v s}$ is observed in the region of high solid concentration $\left(\bar{\varepsilon}_{s} \geq 0.10\right)$. On the other hand, in the region of small $U_{g}$ the value of $d_{v s}$ decreases with increasing $\mu_{l}$ at $\bar{\varepsilon}_{s}=0.13$. In contrast to this, $\mu_{l}$ has little effect on $d_{v s}$ at $\bar{\varepsilon}_{s}=0.20$.

Figure 7 shows that the value of $d_{v s}$ for the column containing $0.46-\mathrm{mm}$ glass beads increases with increasing $U_{g}$, while it decreases with increasing $U_{l}$ or decreasing $\bar{\varepsilon}_{s}$. The decrease in bubble size with increasing $U_{l}$ may be due to the increase in bed mobility resulting from bed expansion.

Figure 8 shows that the relationship between $\bar{U}_{b}$ and $d_{v s}$ is independent of $d_{p}, \bar{\varepsilon}_{s}$ and $\mu_{l}$ in the whole experimental range, and all the data for both the gasliquid and the gas-liquid-solid bubble columns can be correlated by a Davies-Taylor type equation ${ }^{3)}$ as follows:

$$
\bar{U}_{b}=1.3 \sqrt{g d_{v s}}
$$

The coefficient of variation for Eq. (3) is $16 \%$. It is interesting to note that a Davies-Taylor type equation is applicable to correlate the mean rising velocity of bubbles in a gas-solid fluidized bed. ${ }^{6}$

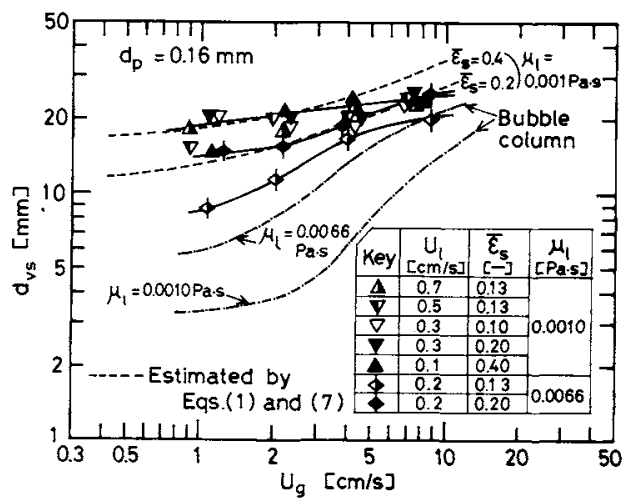

Fig. 6. Volume-surface mean bubble diameter in a slurry bubble column containing $0.16-\mathrm{mm}$ glass beads.

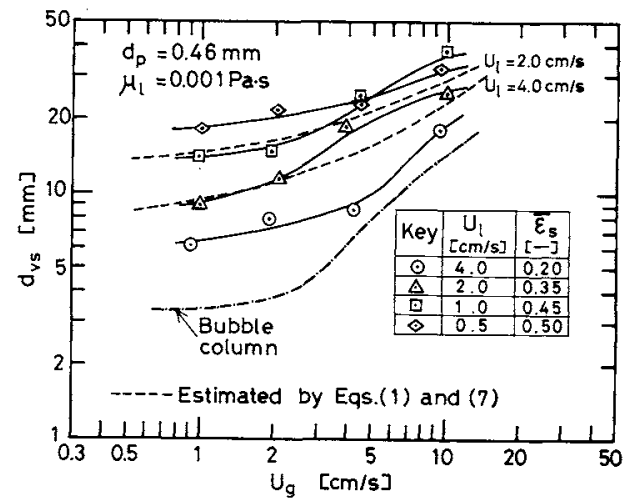

Fig. 7. Volume-surface mean bubble diameter in a slurry bubble column (or in a three-phase fluidized bed) containing $0.46-\mathrm{mm}$ glass beads.

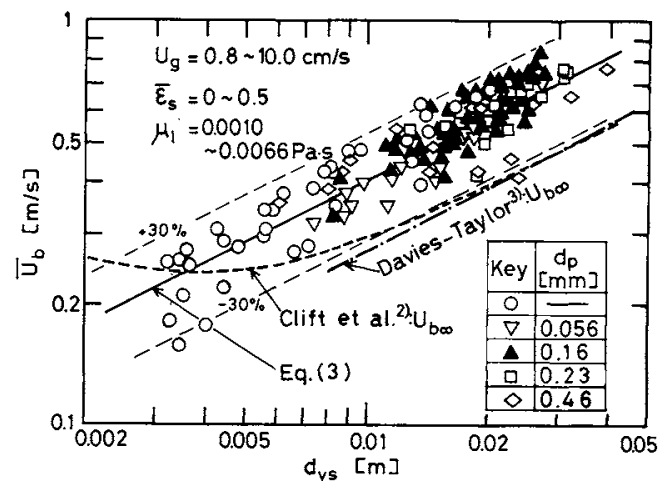

Fig. 8. Relationship between $\bar{U}_{b}$ and $d_{v s}$

Clift et al. ${ }^{2)}$ correlated the rising velocity of a single bubble in pure water, $U_{b \infty}$, over a wide range of bubble diameter. Their correlation coincides with the Davies-Taylor equation at large values of $d_{v s}$. As shown in Fig. 8, the value of $\bar{U}_{b}$ from Eq. (3) is close to that of $U_{b \infty}$ by Clift $e t a{ }^{2}{ }^{2}{ }^{2}$ in the range of small $d_{v s}$, but the former is about $40 \%$ larger than the latter in the range of $d_{v s} \geq 0.01 \mathrm{~m}$.

\subsection{Correlation of volume-surface mean bubble diameter}

In the following section, an attempt is made to correlate $\bar{U}_{b}$ with operating variables. According to 
Wallis, ${ }^{17)}$ the drift flux of gas, $V_{D}$, in gas-liquid twophase flow is defined as

$$
V_{D} \equiv U_{g}\left(1-\bar{\varepsilon}_{g}\right)-U_{l} \bar{\varepsilon}_{g}\left(1-\bar{\varepsilon}_{g}\right) / \bar{\varepsilon}_{l}
$$

where $\bar{\varepsilon}_{l}$ is the mean liquid holdup. Furthermore, $V_{D}$ is represented empirically as follows:

$$
V_{D}=\bar{\varepsilon}_{g} U_{b \infty}\left(1-\bar{\varepsilon}_{g}\right)^{n}
$$

where $n$ is the adjustable parameter. As the value of $\bar{U}_{b}$ is almost proportional to that of $U_{b \infty}$ (Fig. 8), it may be reasonable to replace $U_{b \infty}$ with $k \bar{U}_{b}$ in Eq. (5). It may be assumed that $n=0$ for the case of the heterogeneous flow, ${ }^{17)}$ which is the prevailing flow mode in this work. Consequently, Eq. (5) is reduced to

$$
V_{D}=k \bar{\varepsilon}_{g} \bar{U}_{b}
$$

The relationship between $\bar{\varepsilon}_{g} \bar{U}_{b}$ and $V_{D}$ is shown in Fig. 9, where observed values of $\bar{\varepsilon}_{g}$ are used in the calculation. It is seen that Eq. (6) holds best in the case of $k=1$. The coefficient of variation for the above estimation is about $35 \%$. But it falls to $23 \%$ when the values of $\bar{\varepsilon}_{g}$ estimated from Eq. (1) are used.

From Eqs. (3) and (6), the following equation is derived.

$$
d_{v s}=0.59\left(V_{D} / \bar{\varepsilon}_{g}\right)^{2} / g
$$

Figure 10 compares the values of $d_{v s}$ observed with those calculated by Eq. (7). In the calculation, the value of $\bar{\varepsilon}_{g}$ is estimated from Eq. (1). It is seen that the values of $d_{v s}$ observed for the experimental conditions noted in the figure are correlated fairly well. The coefficient of variation for Eq. (7) is about 30\%. The dashed lines in Figs. 5-7 indicate the values of $d_{v s}$ estimated from Eqs. (7) and (1) under typical conditions. It may be seen that the calculated values agree fairly well with the corresponding data.

Also shown in Fig. 10 are the relationship between the values of $d_{v s}$ observed by various workers $^{1,8,10,15,16)}$ and those calculated from Eq. (7) with their own $\bar{\varepsilon}_{g}$ data. The values of volume-mean bubble diameter of Koide et al.$^{8)}$ for a bubble column with perforated plate as gas distributor are correlated fairly well by Eq. (7). However, the deviation of the estimated value from the observed value becomes large for small hole diameter of the gas distributor. The trend for $d_{v s}$ observed by Akita and Yoshida ${ }^{1)}$ is not consistent with that estimated, but the deviation of estimation is relatively small in the range of their experimental conditions. The data for $d_{v s}$ of other workers are correlated fairly well by Eq. (7), as shown in Fig. 10. The deviation of estimated value from the observed value for the column with aqueous solution of electrolyte ${ }^{5,7,12)}$ is somewhat larger than that for the non-electrolyte system.

Figure 11 shows the relationship between $d_{v s}$ and $d_{p}$

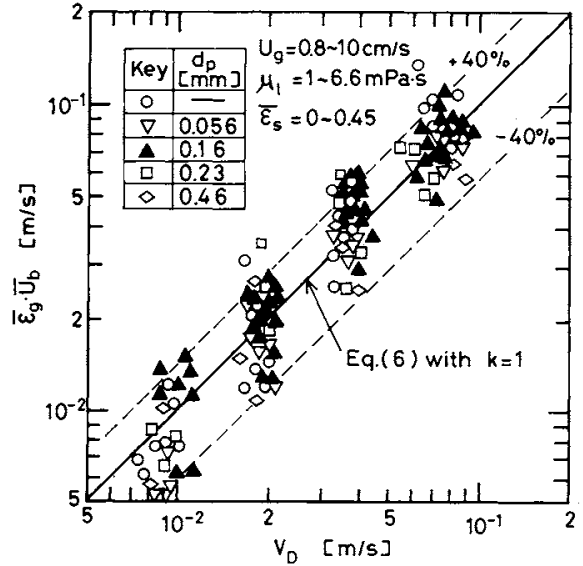

Fig. 9. Correlation of $\bar{U}_{b}$ based on the drift-flux model.

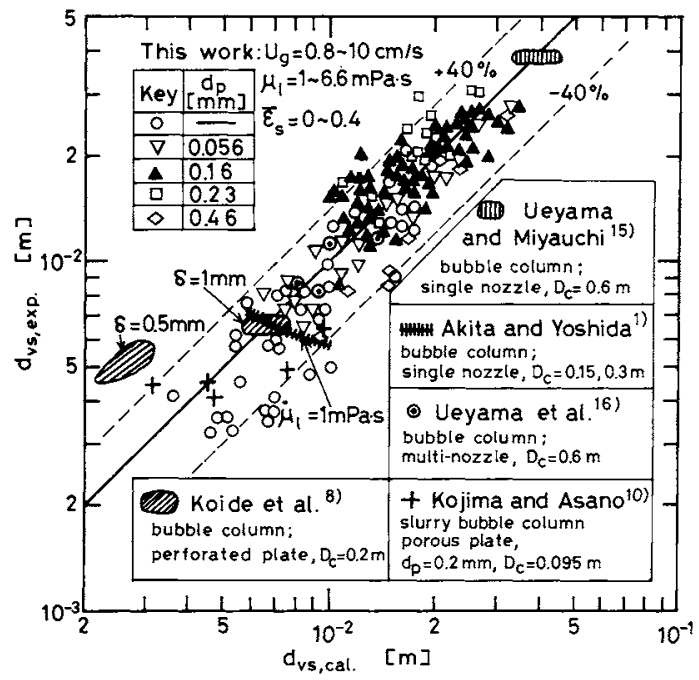

Fig. 10. Comparison of values of $d_{v s}$ estimated with those observed.

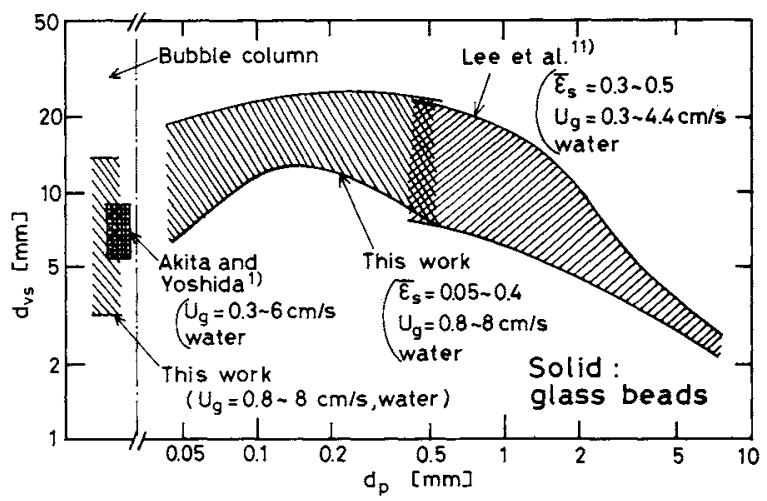

Fig. 11. Effect of $d_{p}$ on $d_{v s}$ for a slurry bubble column and for a three-phase fluidized bed containing glass beads.

observed in this work along with those observed in other systems, i.e., for a bubble column by Akita and Yoshida $^{1)}$ and for a three-phase fluidized bed by Lee et al. ${ }^{11)}$ Allowance should be made for neglecting the effect of operational conditions other than $d_{p}$. It may be seen that the variation of $d_{v s}$ with $d_{p}$ is represented 
by a convex band, and the values of $d_{v s}$ for the slurry bubble column approach those for the bubble column with decreasing $d_{p}$. It may be indicated that the bubble size has a maximum at about $d_{p}=0.2 \mathrm{~mm}$ for air-water-glass beads systems.

\section{Conclusions}

1) When solid particles are added at a small gas velocity in a bubble column, the bubble length distribution, $F_{l}$, shifts to a large-size region and the bubble velocity distribution, $F_{v}$, shifts to a large-velocity region. However, the effect of the presence of solid particles on $F_{l}$ and $F_{v}$ becomes small as the particle diameter decreases or the liquid viscosity increases.

2) The trends for the mean bubble length, $\bar{L}_{b}$, and the mean bubble rising velocity, $\bar{U}_{b}$, are similar to those for $F_{l}$ and $F_{v}$, respectively.

3) The volume-surface mean bubble diameter, $d_{v s}$, which is assumed to be 1.5 times $\bar{L}_{b}$, is correlated as a function of $\bar{U}_{b}$ by a Davies-Taylor type equation, Eq. (3). $\bar{U}_{b}$ is correlated by Eq. (6) on the basis of the driftflux model. Consequently, $d_{v s}$ is correlated in terms of operational variables and phase holdups by Eq. (7).

4) The mean bubble size may become largest at a particle diameter of about $0.2 \mathrm{~mm}$ for the air-waterglass beads system.

\section{Acknowledgment}

The authors are grateful to Mr. T. Matsuoka (Dept. of Electrical Engineering, Tottori University) and Mr. M. Shigemoto for their participation in our manufacture of a computer-controlled data acquisition system, and express appreciation to Mr. A. Mōri, Mr. Y. Kodera and Mr. T. Ishitobi for their assistance in experiments.

\section{Nomenclature}

$\begin{array}{llr}C_{s} & =\text { solid concentration in slurry } & {\left[\mathrm{kg} / \mathrm{m}^{3}\right]} \\ D_{c} & =\text { column diameter } & {[\mathrm{m}]} \\ d_{p} & =\text { particle diameter } & {[\mathrm{m}]} \\ d_{v s} & =\text { volume-surface mean bubble diameter } & {[\mathrm{m}]} \\ F_{l} & =\text { cumulative bubble length distribution } & {[\%]} \\ F_{v} & =\text { cumulative bubble velocity distribution } & {[\%]} \\ g & =\text { gravitational acceleration } & {\left[\mathrm{m} / \mathrm{s}^{2}\right]} \\ k & =\text { constant in Eq. (6) } & {[-]} \\ L_{b} & =\text { vertical bubble length (chord length) } & {[\mathrm{m}]} \\ \bar{L}_{b} & =\text { arithmetic mean of } L_{b} \text { in column } & {[\mathrm{m}]} \\ L_{m} & =\text { median of bubble length distribution } & {[\mathrm{m}]} \\ U_{b} & =\text { bubble rising velocity } & {[\mathrm{m} / \mathrm{s}]} \\ \bar{U}_{b} & =\text { arithmetic mean of } U_{b} \text { in column } & {[\mathrm{m} / \mathrm{s}]} \\ U_{b \infty} & =\text { terminal rising velocity of a single bubble } & {[\mathrm{m} / \mathrm{s}]} \\ U_{g} & =\text { superficial gas velocity } & {[\mathrm{m} / \mathrm{s}]} \\ U_{l} & =\text { superficial liquid velocity } & {[\mathrm{m} / \mathrm{s}]} \\ U_{m} & =\text { median of bubble velocity distribution } & {[\mathrm{m} / \mathrm{s}]}\end{array}$

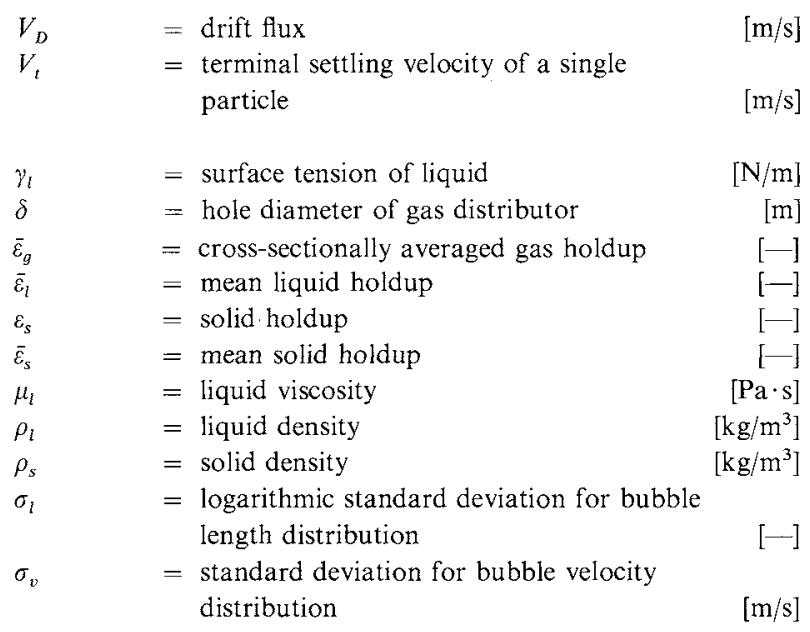

\section{Literature Cited}

1) Akita, K. and F. Yoshida: Ind. Eng. Chem., Process Des. Dev., 13, 84 (1974).

2) Clift, R., J. R. Grace and M. E. Weber: "Bubbles, Drops, and Particles," p. 169, Academic Press, New York (1978).

3) Davies, R. M. and G. I. Taylor: Proc. Roy. Soc., A200, 375 (1950).

4) Deckwer, W.-D., Y. Louisi, A. Zaidi and M. Ralek: Ind. Eng. Chem., Process Des. Dev., 19, 699 (1980).

5) Godbole, S. P., A. Schumpe, Y. T. Shah and N. L. Carr: AIChE J., 30, 213 (1984).

6) GOLFERs: Kagaku Kogaku Ronbunshu, 8, 464 (1982).

7) Kato, Y., A. Nishiwaki, T. Kago, T. Fukuda and S. Tanaka: Kagaku Kōgaku, 36, 1333 (1972).

8) Koide, K., T. Hirahara and H. Kubota: Kagaku Kögaku, 30, $712(1966)$

9) Koide, K., A. Takazawa, M. Kōmura and H. Matsunaga: $J$. Chem. Eng. Japan, 17, 459 (1984).

10) Kojima, H. and K. Asano: Kagaku Kogaku Ronbunshu, 6, 46 (1980).

11) Lee, J. C., A. J. Sherrard and P. S. Buckley: "Fluidization and Its Applications," p.407, Cepadues-Editions, Toulouse (1974).

12) Schumpe, A. and W.-D. Deckwer: Ind. Eng. Chem., Process Des. Dev., 21, 706 (1982).

13) Shah, Y. T., S. Joseph, D. N. Smith and J. A. Ruether: Ind. Eng. Chem., Process Des. Dev., 24, 1096 (1985).

14) Ueyama, K. and T. Miyauchi: Kagaku Kogaku Ronbunshu, 2, 430 (1976).

15) Ueyama, K. and T. Miyauchi: Kagaku Kogaku Ronbunshu, 3, 19 (1977).

16) Ueyama, K., S. Morooka, K. Koide, H. Kaji and T. Miyauchi: Ind. Eng. Chem., Process Des. Dev., 19, 592 (1980).

17) Wallis, G. B.: "One-dimensional Two-phase Flow," McGraw-Hill, New York (1969).

18) Yasunishi, A., M. Fukuma and K. Muroyama: Kagaku Kogaku Ronbunshu, 12, 420 (1986).

19) Yasunishi, A., M. Fukuma and K. Muroyama: J. Chem. Eng. Japan, 19, 444 (1986). 